University of Nebraska - Lincoln

DigitalCommons@University of Nebraska - Lincoln

$10-10-2005$

\title{
Improved methods for isolating DNA from Ostertagia ostertagi eggs in cattle feces
}

Aaron F. Harmon

Dante S. Zarlenga

Michael B. Hildreth

Follow this and additional works at: https://digitalcommons.unl.edu/usdaarsfacpub

This Article is brought to you for free and open access by the U.S. Department of Agriculture: Agricultural Research Service, Lincoln, Nebraska at DigitalCommons@University of Nebraska - Lincoln. It has been accepted for inclusion in Publications from USDA-ARS / UNL Faculty by an authorized administrator of DigitalCommons@University of Nebraska - Lincoln. 


\title{
Improved methods for isolating DNA from Ostertagia ostertagi eggs in cattle feces
}

\author{
Aaron F. Harmon ${ }^{a}$, Dante S. Zarlenga ${ }^{c}$, Michael B. Hildreth ${ }^{a, b, *}$ \\ ${ }^{\mathrm{a}}$ Department of Biology and Microbiology, South Dakota State University, Brookings, SD 57007, USA \\ ${ }^{\mathrm{b}}$ Department of Veterinary Sciences, South Dakota State University, Brookings, SD 57007, USA \\ ${ }^{\mathrm{c}}$ USDA, ARS, Bovine Functional Genomics Lab, Beltsville, MD 20705, USA
}

Received 28 September 2005; accepted 10 October 2005

\begin{abstract}
A multiplex PCR assay for differentiating strongyle eggs from cattle has recently been described; however, the egg disruption and DNA extraction procedures, though effective, are inadequate for large studies or clinical application. The purpose of this research was to evaluate methods for disrupting trichostrongyle eggs, then assess commercial kits for extracting egg DNA using Ostertagia ostertagi as a model species. Egg disruption procedures tested included probe sonication, bath sonication, bead beating, boiling, microwaving, proteinase K/SDS digestion, freezing, and various combinations of the above with the incorporation of sodium dodecyl sulfate. These procedures were evaluated in conjunction with four commercial DNA extraction kits: DNA Stool mini kit and DNeasy Plant kit (Qiagen), Fast DNA kit (QBiogene), and the MAP extraction kit (Tetracore). Results showed that egg disruption was best accomplished with the bead beater and ceramic beads, resulting in $100 \%$ disruption within 1 min. When DNA extraction was preceded by the isolation of eggs from feces, all procedures except the Fast DNA kit produced PCR-ready DNA from at least two eggs. The DNeasy Plant kit allowed consistent detection of DNA released from one egg. Due to the morphological similarities among trichostrongyle eggs in ruminants, strongyle eggs in equids, and hookworm eggs, the methods described herein may have broad application to other nematodes.
\end{abstract}

(C) 2005 Elsevier B.V. All rights reserved.

Keywords: Ostertagia; Nematode eggshell disruption; DNA extraction; Bovine; PCR diagnosis; Strongyle

\section{Introduction}

Trichostrongyle nematodes in cattle have a large economical impact in the U.S. These nematodes have

\footnotetext{
* Corresponding author at: Department of Biology and Microbiology, NPB rm 252 Rotunda Ln, South Dakota State University, Brookings, SD 57007, USA. Tel.: +1 605688 4562; fax: +16056885624 .

E-mail address: michael.hildreth@sdstate.edu (M.B. Hildreth).
}

traditionally been difficult to differentiate because of the need for coproculture to identify different genera from the egg stage. Recently, a multiplex PCR for differentiating trichostrongyle eggs isolated with a standard zinc sulfate flotation protocol from cattle feces has been described by Zarlenga et al. (2001). In this method, DNA is extracted from eggs in a multiplestep procedure that first requires probe sonication followed by proteinase $\mathrm{K} /$ sodium dodecyl sulfate 
(SDS) digestion. The DNA is then extracted with phenol-chloroform and precipitated with ethanol. This protocol provides excellent sensitivity with a detection level equivalent to 0.05 eggs when DNA is diluted to its detection limit; however, the multi-step approach makes it less practical for large numbers of samples, especially where sample-to-sample contamination cannot be tolerated. Protocols for recovering DNA from other nematodes (e.g. hookworms and horse strongyles) with similar "strongyle-type" eggs have also been described using various levels of physical, chemical, or enzymatic steps that differ in their degree of convenience and sensitivity. One of the simplest procedures involves adding eggs purified by fecal flotation directly into a standard PCR without prior DNA extraction (Schnieder et al., 1999). In this method, single eggs could be detected; however, the ease and reproducibility of using heat to disrupt eggs from disparate species was not evaluated nor was this method attempted on anything but a few samples at one time. Christensen et al. (1994) described a protocol that first degrades the hard nematode eggshell with chitinase followed by proteinase K/SDS treatment. They were able to detect at least 25 eggs from the four species of trichostrongyles that were studied; however, this approach was developed for solid-phase hybridization where fecal impurities can be tolerated.

Recent studies involving the diagnosis of human hookworm have demonstrated DNA isolation directly from fecal samples without prior egg concentration (Verweij et al., 2001; Gruijter et al., 2005). Whole feces were processed in polyvinyl polypyrolidone at $100{ }^{\circ} \mathrm{C}$ followed by proteinase K/SDS treatment and column chromatography to purify the DNA prior to PCR amplification. In one study, roughly $90 \%$ of coproculture-diagnosed cases of human hookworm were identified with this detection system; though Gruijter et al. (2005) expressed concern over the sensitivity of this approach.

Consistent among most published studies is the lack of microscopic evaluation for the effectiveness of any given approach to disrupt the eggs; consequently, it is possible that assay sensitivity and reliability can be enhanced by developing methodology that insures maximum eggshell disruption. The purpose of the present study was to evaluate alternative methods for consistently isolating trichostrongyle egg DNA beginning with the disruption of the eggs. Subsequent to choosing the best method for egg disruption, we evaluated four commercial kits designed to extract DNA either from fecal samples or plants. The extracted DNA was assayed for integrity and sensitivity by PCR using primers that specifically amplify Ostertagia ostertagi, a gastrointestinal nematode of cattle.

\section{Materials and methods}

\subsection{Egg isolation}

All eggs and fecal samples used in this study came from calves maintained in concrete pens and infected with $O$. ostertagi as described by Zarlenga et al. (2001). Eggs from feces were isolated and counted using a modified Wisconsin sucrose flotation with the second centrifugation step omitted (Cox and Todd, 1962). Eggs were then recovered by adding each slide to a $50 \mathrm{ml}$ centrifuge tube containing $45 \mathrm{ml}$ distilled water, vortexing, and centrifuging at $2000 \times g$. Collected eggs were transferred to $1.5 \mathrm{ml}$ of distilled water or $0.1 \%$ SDS for treatment as indicated in Table 1 .

\subsection{Egg disruption}

Egg isolation without further treatment was used as a control to evaluate the efficacy of each protocol (Table 1). These included: (1) SDS $0.1 \%$ as a solvent; (2) storage overnight at $-20{ }^{\circ} \mathrm{C}$ in distilled water; (3) bath sonication in a Fisher Ultrasonic cleaner FS20 for $60 \mathrm{~min}$; (4) bath sonication for $60 \mathrm{~min}$ with $0.1 \%$ SDS as a solvent; (5) immersion in boiling water for 10 min; (6) heating in a microwave oven (Whirlpool Time Master microwave oven Model MW3520XP set to high) for $1 \mathrm{~min}$; (7) probe sonication for $1 \mathrm{~min}$ at 25 watts with a Vibra Cell Sonicator model VC50 (Sonics and Materials Inc., Newtown, CT); (8) proteinase $\mathrm{K}(2 \mathrm{mg} / \mathrm{ml}) / \mathrm{SDS}(2 \%)$ digestion at $70{ }^{\circ} \mathrm{C}$ for $2 \mathrm{~h}$ following a $10 \mathrm{~min}$ boiling water treatment; (9) bath sonication in combination with boiling water treatment or (10) with microwave treatment; (11) agitation in a Mini BeadBeater-8 (BioSpec, Bartlesville, OK) operated at the homogenize setting for varying time periods with various sample lysing matrices. The disruption times evaluated were $1-3 \mathrm{~min}$. The lysing matrices evaluated were a $6.5 \mathrm{~mm}$ ceramic bead with $0.25 \mathrm{~g}$ of ceramic 
Table 1

Recovery of eggs following different egg lysis methods

\begin{tabular}{|c|c|c|c|c|}
\hline No. & Method egg lysis & Solution & Recovered eggs (\%) & S.D. $(\%)$ \\
\hline & None (control) & Water & 86.6 & 7 \\
\hline 1 & None (control) & $0.1 \%$ SDS & $58.9^{\mathrm{a}}$ & 24 \\
\hline 2 & Overnight freezing & Water & $87.4^{\mathrm{a}}$ & 17 \\
\hline 3 & Bath sonication & Water & $72.0^{\mathrm{a}}$ & 17 \\
\hline 4 & Bath sonication & $0.1 \%$ SDS & $83.3^{\mathrm{a}}$ & 15 \\
\hline 5 & Boiling water-bath & $0.1 \%$ SDS & $56.0^{\mathrm{a}}$ & 12 \\
\hline 6 & Microwave & $0.1 \%$ SDS & $90.7^{\mathrm{a}}$ & 9 \\
\hline 7 & Probe sonication & Water & $12.0^{\mathrm{c}}$ & 18 \\
\hline 8 & Boiling water bath/protinease K/SDS digestion & Water & $13.0^{\mathrm{c}}$ & 18 \\
\hline 9 & Bath sonication/boiling water-bath & $0.1 \%$ SDS & $44.4^{\mathrm{b}}$ & 20 \\
\hline 10 & Bath sonication/microwave & $0.1 \%$ SDS & $55.7^{\mathrm{a}}$ & 39 \\
\hline \multirow[t]{6}{*}{11} & Bead beater ( $3 \mathrm{~min}$ ) zirconia/silica beads & Water & $0.0^{\mathrm{c}}$ & 0 \\
\hline & Bead beater $(2 \mathrm{~min})$ zirconia/silica beads & Water & $4.0^{\mathrm{c}}$ & 9 \\
\hline & Bead beater $(3 \mathrm{~min})$ glass powder & Water & $29.0^{\mathrm{c}}$ & 19 \\
\hline & Bead beater $(3 \mathrm{~min})$ ceramic beads & Water & $0.0^{\mathrm{c}}$ & 0 \\
\hline & Bead beater ( 2 min $)$ ceramic beads & Water & $0.0^{\mathrm{c}}$ & 0 \\
\hline & Bead beater ( 1 min) ceramic beads & Water & $0.0^{\mathrm{c}}$ & 0 \\
\hline
\end{tabular}

\footnotetext{
${ }^{\mathrm{a}}$ Results were not significant from the water control $p>0.05$

${ }^{\mathrm{b}}$ Results were significant from the water control $p<0.05$.

${ }^{\mathrm{c}}$ Results were significant from water control $p<0.001$.
}

chips (Qbiogene Lysing Matrix A), a 6 mm glass bead with $0.35 \mathrm{~g}$ of glass powder, or with $0.90 \mathrm{~g}$ zirconia/ silica beads only (Tetracore, Gaithersburg, MD). With methods $4-6,9$, and $10,0.1 \%$ SDS was used to enhance disruption. After each treatment, eggs were enumerated microscopically, and the percent recovery was calculated. The percentages recorded in Table 1 represent the mean of five egg samples tested. The treatment effects were compared based on a oneway ANOVA analysis using GraphPad Instat software (http://www.graphpad.com).

To evaluate amplification by PCR without prior disruption (Schnieder et al., 1999), isolated eggs were placed directly into PCR tubes containing all reagents and amplification was conducted as described below. After PCR, the tubes were centrifuged to pellet debris. The supernatant was subjected to agarose gel electrophoresis and visualized by ethidium bromide staining, and the pellet was examined for the presence of intact eggs.

\subsection{DNA extraction from eggs}

The DNA extraction kits that were tested included the (A) Qiagen DNA Stool Kit (Valencia, CA), (B)
Qiagen DNeasy Plant Mini kit, (C) QBiogene Fast DNA kit (Irvine, CA), and (D) Tetracore DNA extraction kit (Gaithersburg, MD). Manufacturer's protocols were followed for all extractions. When kits recommended direct addition of fecal samples without prior isolation of eggs, samples were evaluated with and without an egg isolation step. To disrupt the eggshells, the bead beater was used for 3 min with ceramic or zirconia/silica beads.

The Qiagen DNA Stool kit uses a chemical lysis step performed at $95^{\circ} \mathrm{C}$. A comparison was made using these conditions with and without the bead beater. The lysis buffer (ASL) provided with the kit was evaluated for its ability to lyse eggs at $95{ }^{\circ} \mathrm{C}$ for $10 \mathrm{~min}$. The samples were then centrifuged and the resultant pellets observed for eggs.

The Qbiogene Fast DNA kit offers three buffer choices: CLS-VF for plants, CLS-Y for yeast, and CLS-TC for cell cultures and human tissue. Each buffer was evaluated as was the ability of the CLS-VF lysis buffer to extract DNA from samples without prior egg isolation.

The Tetracore kit is part of the MAP diagnostic system designed for detecting bacteria in fecal samples. This kit recommends that $1 \mathrm{~g}$ of sample be 
vortexed with $2 \mathrm{ml}$ of TE buffer. After allowing the debris to settle, the supernatant is placed in a tube containing zirconia/silica beads then treated with the bead beater. The kit also includes glass beads that were evaluated with isolated eggs (Table 2).

To assess the sensitivity of the DNA extraction kits, samples containing one, two, and five eggs were treated and analyzed by PCR. Eggs were subjected to prior isolation as described above, then microscopically transferred into a $2.0 \mathrm{ml}$ centrifuge tube prior to extracting the DNA.

\subsection{PCR evaluation of commercial kits}

The primers and protocols used to evaluate the commercial kits were developed elsewhere (Zarlenga et al., 2001). The primers encompass the small subunit rDNA (ssrDNA) (F 5'TAAAAGTCGTA ACAAGGTATCTGTAGGT) and the first internal transcribed spacer (ITS1) (R 5'GTCTCAAGCTCA ACCATAACCAACCATTGG) of $O$. ostertagi. The target DNA was amplified using a Perkin-Elmer 2400 thermocycler and Amplitaq Gold PCR Mastermix (0.25 U/ $\mu$ l Taq Pol., 200 uM each DNTP, $2.5 \mathrm{mM} \mathrm{MgCl}_{2}$, Applied Biosystems, Foster City, CA). Amplification was carried out as follows: denaturation at $95^{\circ} \mathrm{C}$ for $10 \mathrm{~min}$, then amplification for 40 cycles at $95{ }^{\circ} \mathrm{C}$ for $1 \mathrm{~min}, 60^{\circ} \mathrm{C}$ for $1 \mathrm{~min}$, and $72{ }^{\circ} \mathrm{C}$ for $2 \mathrm{~min}$ with a final elongation step of $72{ }^{\circ} \mathrm{C}$ for $7 \mathrm{~min}$. PCR products were separated on a $3 \%$ agarose gel, stained with ethidium bromide, and captured with a Bio-Rad ChemiDoc XRS gel imaging system (Hercules, CA) using Bio-Rad Quantity-One software version 4.5.2.

\section{Results}

\subsection{Egg disruption}

When isolated eggs were simply suspended in distilled water and recounted (i.e. water control group), $86.6 \%$ of the eggs were recovered (Table 1). With the addition of SDS, 58.9\% of the eggs were recovered, which failed to be statistically different from the controls. However, when eggs in SDS were exposed to a combination of bath sonication and boiling temperatures, more eggs were disrupted than in the control group $(p<0.05)$. This was also true for eggs exposed to probe sonication, digested with proteinase K/SDS, or agitated in the bead beater with a glass bead and powder or zirconia/silica beads $(p<0.001)$. Eggs showed $100 \%$ disruption when the bead beater system was used in conjunction with zirconia/silica beads for $3 \mathrm{~min}$ or ceramic beads for $1 \mathrm{~min}$. Recovery rates for all of the remaining treatment groups (Table 1) were not statistically different than the water control group $(p>0.05)$. Recovery rates for intact eggs subjected directly to PCR were similar to the water control (mean of $88 \%$, S.D. $=18 \%, p>0.05$ ), suggesting incomplete disruption and therefore limited amounts of DNA available for amplification. This was corroborated by the

Table 2

PCR results from DNA extraction kits with alternative pretreatments

\begin{tabular}{|c|c|c|c|}
\hline Kit & Treatment & Mean eggs/sample & PCR results ${ }^{\mathrm{a}}$ \\
\hline \multirow[t]{4}{*}{ QBiogene Fast DNA } & Egg isolation and lysis buffer CLS-TC & 30 &,,,,----- \\
\hline & Egg isolation and lysis buffer CLS-VF & 11 &,,,,+++++ \\
\hline & Egg isolation and lysis buffer CLS-Y & 30 &,,,,+---- \\
\hline & Lysis buffer CLS-VF & 15 &,,,,----- \\
\hline \multirow[t]{3}{*}{ Qiagen QIAamp DNA Stool mini-kit } & None & 15 &,,,,++ \pm \pm \pm \\
\hline & Egg isolation & 30 &,,,,++--- \\
\hline & Egg isolation and ceramic beads & 6 &,,,,+++++ \\
\hline \multirow[t]{3}{*}{ Tetracore MAP kit } & Zirconia beads & 30 &,,,,++--- \\
\hline & Egg isolation and glass beads & 19 &,,,,+++++ \\
\hline & Egg isolation and zirconia beads & 34 &,,,,+++++ \\
\hline Qiagen DNeasy Plant kit & Egg isolation and ceramic beads & 9 &,,,,+++++ \\
\hline
\end{tabular}

\footnotetext{
${ }^{\text {a }}$ Results are from five samples; +: PCR product of high yield; \pm : PCR product of low yield; -: no PCR product.
} 
absence of PCR products observed by agarose gel electrophoresis.

\subsection{Extraction of PCR quality DNA}

With egg numbers ranging from 6 to 34 , each kit was able to extract PCR quality DNA when eggs were first isolated and lysed with the bead beater system (Table 2). The Fast DNA kit was only effective in the presence of the CLS-VF buffer. The MAP detection kit was equally effective with both bead types provided. The Tetracore kit and Qiagen's Stool kit extracted sufficient egg DNA directly from the fecal sample to generate weak PCR bands, but only when gel images were computer enhanced using the gel imaging software. When the Qiagen ASL buffer was examined for intact eggs, 60\% of the input eggs were recovered (S.D. $=14 \%$ ).

The DNeasy Plant kit using isolated eggs and the bead beater was able to extract amplifiable DNA from as few as 9 eggs and was the only system able to reproducibly extract amplifiable DNA from purified samples containing one egg (Table 3). The MAP, QIAamp Stool, and the DNeasy Plant extraction kit were able to detect DNA from 2 eggs in each of 5 purified samples tested whereas the Fast DNA kit was able to generate PCR product in only two of five examined samples each containing DNA from 5 eggs. All of the other kits were able to amplify all of the five egg samples (Table 3).

Table 3

PCR Results for samples containing one and two eggs

\begin{tabular}{lll}
\hline Kit & Eggs/sample $^{\mathrm{b}}$ & PCR results $^{\mathrm{a}}$ \\
\hline QBiogene Fast DNA & 1 &,,,,----- \\
& 2 &,,,,----- \\
& 5 &,,,, \pm \pm--- \\
Tetracore MAP & 1 &,,,,----- \\
& 2 &,,,,++ \pm \pm- \\
QIAamp DNA Stool mini-kit & 1 &,,,,+++++ \\
& 2 &,,,,+++-- \\
& 5 &,,,,++ \pm-- \\
Qiagen DNeasy Plant mini-kit & 1 &,,,,++++- \\
& 2 &,,,, \pm \pm \pm \pm \pm \\
& 5 &,,,,+++ \pm \pm \\
& &,,,,+++++ \\
\hline
\end{tabular}

\footnotetext{
${ }^{a}$ Results are from five samples; + : PCR product of high yield; \pm : PCR product of low yield; -: no PCR product.

${ }^{\mathrm{b}}$ Eggs were microscopically identified and added to kit provided lysis buffer.
}

\section{Discussion}

Historically, diagnosis of gastrointestinal nematodes has required the microscopic examination of fecal contents for the presence of eggs following either flotation or sedimentation protocols. In many cases, eggs from phylogenetically related nematodes are extremely difficult to reproducibly differentiate; however, in recent years, DNA-based tests have enabled unequivocal identification of even closely related species. The same concentration techniques used for microscopic analysis can also be used to increase the sensitivity and reliability of PCR assays, first by increasing egg concentration and second by separating eggs from a substantial portion of inhibitors that affect PCR amplification. This concentration step is particularly important because many commercially available DNA extraction kits are limited by sample volume. As illustrated in the present study, it may be prudent to use PCR analysis as a confirmation of, and more specific addendum to, microscopic analysis as described by Cox and Todd (1962) where PCR can be restricted to samples positive for eggs in providing final assignment to the infectious agent(s).

To maximize the sensitivity of PCR-based egg diagnosis, one must first maximize egg disruption. In the present study, shelled eggs were found to varying degrees in all of the treatment groups except those using the bead beater with ceramic or zirconia/silica beads, suggesting that this treatment group achieves maximum sensitivity. When proteinase K/SDS digestion was used, only a few eggs could be recovered. Mechanical disruption provides an advantage over chemical and enzymatic methods because it does not require the addition of reagents that may interfere with subsequent reactions; however, mechanical disruption, as with sonication, can affect the size of the target DNA. Nonetheless, the results from the present study in conjunction with those presented elsewhere (Zarlenga et al., 2001) raise concerns about the effectiveness and sensitivity of DNA based tests that do not fully disrupt the eggs prior to analysis (e.g. Schnieder et al., 1999).

Organic extraction has been shown to result in PCR ready DNA from strongyle eggs isolated from fecal samples (Zarlenga et al., 1997, 2001), though PCR inhibitors are not completely removed in the process. Multiple extractions, however, are labor intensive, 
time consuming, and not cost effective. Commercial DNA extraction kits allow for rapid extraction that is reproducible. Some kits are designed for specific use with fecal samples, i.e. Qiagen QIAamp DNA Stool kit, Tetracore MAP detection kit, where PCR inhibitors abound, while others are designed for use in plants, i.e. QBiogene Fast DNA kit with CLS-VF buffer and Qiagen DNeasy Plant Kit, where high concentrations of complex polysaccharides are present that have been shown also to inhibit PCR (Lurdes et al., 1997). Since plant material is the major composition of ruminant fecal matter, it is of little surprise that both kits were able to extract PCR quality DNA.

Disruption of all eggs was achieved after a 3 min treatment using the bead beater, though subsequent experiments showed that 1 min was sufficient. Even though there is the potential for DNA shearing with the bead beater, the speed, closed tube arrangement, and hands off treatment during disruption make this a superior tool for eggshell disruption compared to probe sonication.

In conclusion, it should be possible to extend the results from this study involving $O$. ostertagi to extracting DNA from trichostrongyle eggs in general. In addition, morphological and biochemical similarities between trichostrongyle eggs and hookworm eggs suggest that recommendations made herein would form a sound basis upon which to isolate DNA from hookworm eggs as well. In this regard, our data demonstrate that preliminary enrichment of eggs through sugar flotation, followed by $1 \mathrm{~min}$ treatment with a bead beater system involving ceramic beads, then DNA extraction with one of several available commercial kits is sufficient for isolating DNA from eggs. Of the kits tested, the DNeasy plant kit should be used when maximum sensitivity is desired; however, if speed is more desirable, acceptable results can be achieved with the Fast DNA kit which utilizes fewer steps, though the detection limit in our hands was no less than 11 Ostertagia eggs.

\section{Acknowledgements}

This work was supported by the South Dakota State University Agricultural Experiment Station, and was approved for publication as Journal Series No. 3524 by the Director, Agricultural Experiment Station, South Dakota State University. We would like to thank Brian Lucas, Dr. Beverly Mangold, Shelly Weeks, Dr. Jane Christopher-Hennings and Dr. Andy DeRosa for their contribution to the project.

\section{References}

Christensen, C.M., Zarlenga, D.S., Gasbarre, L.C., 1994. Ostertagia, Haemonchus, Cooperia, and Oesophagostomum: construction of genus-specific DNA probes to differentiate important parasites of cattle. Exp. Parasitol. 78, 93-100.

Cox, D.D., Todd, A.C., 1962. Survey of gastrointestinal parasitism in Wisconsin dairy cattle. J. Am. Vet. Med. Assoc. 141, 706709.

Gruijter, J.M., van Lieshout, L., Gasser, R., Verweij, J.J., Brienen, E.A.T., Ziem, J.B., Yelifari, L., Polderman, A.M., 2005. Polymerase chain reaction-based differential diagnosis of Ancylostoma duodenale and Necator americanus infections in humans in northern Ghana. Trop. Med. Int. Health 10 (6), 574-580.

Lurdes, M., Bonnemaison, D., Vekris, A., Petry, K.G., Bonnet, J., Vidal, R., Cabrita, J., Megraud, F., 1997. Complex polysaccharides as PCR inhibitors in feces: Helicobacter pylori model. J. Clin. Microbiol. 35, 995-998.

Schnieder, T., Heise, M., Epe, C., 1999. Genus-specific PCR for the differentiation of eggs or larvae from gastrointestinal nematodes of ruminants. Parasitol. Res. 85, 895-898.

Verweij, J.J., Pit, D.S.S., van Lieshout, L., Baeta, S.M., Dery, G.D., Gasser, R.B., Polderman, A.M., 2001. Determining the prevalence of Oesophagostomum bifurcum and Necator americanus infections using specific PCR amplification of DNA from faecal samples. Trop. Med. Int. Health 6 (9), 726-731.

Zarlenga, D.S., Chute, M.B., Gasbarre, L.C., Boyd, P.C., 2001. A multiplex PCR assay for differentiating economically important gastrointestinal nematodes of cattle. Vet. Parasitol. 97, 199209.

Zarlenga, D.S., Gasbarre, L.C., Boyd, P.C., Leighton, E., Lichtenfels, J.R., 1997. Identification and semi-quantitation of Ostertagia ostertagi eggs by enzymatic amplification of ITS-1 sequences. Vet. Parasitol. 77, 245-257. 